\title{
EL TÁNDEM VIGO-MONDARIZ EN LOS INICIOS DEL TURISMO MODERNO EN GALICIA
}

\section{THE VIGO-MONDARIZ TANDEM IN EARLY MODERN TOURISM IN GALICIA}

\author{
Margarita Barral Martínez ${ }^{1}$ \\ Universidade de Santiago de Compostela
}

Entregado el 28-5-2013 y aceptado el 26-6-2013.

\begin{abstract}
Resumen: Los años que van desde el último cuarto del siglo XIX hasta la I Guerra Mundial corresponden a uno de los períodos fundamentales de la historia de Europa. La idea de progreso pretendía resumirlo todo y fue también en este ambiente donde tuvo lugar la eclosión del turismo moderno. Pero su desarrollo vino a ser la evolución del termalismo y los baños de mar de orientación cultural burguesa precedente. Para el caso de Galicia, los núcleos de Vigo como polo industrial y el vecino balneario de Mondariz destacaron como lugares de referencia en la región noroeste de la geografía española desde finales del siglo XIX en el desarrollo del ocio terapéutico, en consonancia con lo que estaba sucediendo en el resto del continente. Con este texto pretendemos aproximarnos a la realidad de Vigo y del vecino balneario de Mondariz, a unos treinta y cinco kilómetros de distancia, desde finales del siglo XIX, cuando el turismo se potencia como sector en auge mediante la explotación de las casas de baños de mar y de los baños termales del balneario, lo que situó el enclave en el mapa de los turistas desde comienzos del siglo XX.
\end{abstract}

${ }^{1}$ Departamento de Historia Contemporánea y de América de la USC. Este trabajo forma parte de los proyectos e investigación HAR2011-22905 (MICINN - actual MINECO-) y EM 2012/12 (Xunta de Galicia), dirigidos por la autora del texto. Una primera versión del artículo fue presentada en el XI Congreso de la AHC, que tuvo lugar en la Universidad de Granada entre los días 12 y 15 de septiembre de 2012. 
Palabras clave: Termalismo, baños de mar, turismo moderno, Vigo, Mondariz.

\begin{abstract}
The years from the last quarter of the nineteenth century to World War I are one of the key periods in the history of Europe. The idea of progress was intended to summarize everything, and it was also in this environment where modern tourism emerged, but the development of the latter came to be the evolution of the hot springs and sea bathing typical of the preceding bourgeois culture. In the case of Galicia, the hubs of Vigo as industrial center and the neighboring resort of Mondariz stood out as northwest Spain's landmarks in the development of therapeutic leisure from the late nineteenth century, in line with what was happening in the rest of the continent. With this text we intend to approach the reality of Vigo and the Mondariz spa, about thirty-five miles away from each other, from the late nineteenth century, when tourism was promoted as a booming sector through the exploitation of sea bath houses and Mondariz hot springs, which put the location on tourists' map from the early twentieth
\end{abstract} century.

Key words: Spas, sea baths, modern tourism, Vigo, Mondariz. 
El período que se extiende desde el último cuarto del siglo XIX hasta la Primera Guerra Mundial corresponde a una de las etapas fundamentales de la historia de Europa, cuando se inician los principales cambios políticos, económicos y sociales destinados a condicionar la evolución del Viejo Continente hasta la actualidad. La palabra «progreso» se hacía con el protagonismo de la época y el ferrocarril logró un desarrollo extraordinario que disparó la economía y dinamizó la actividad industrial.

Las insalubres condiciones de vida de las ciudades europeas tras la implantación de la Revolución Industrial favorecieron la contraposición «ciudad frente a balneario» (higienismo²), lo que también potenció el desarrollo del termalismo y de la balneoterapia precedentes entre las capas altas de la sociedad. Los gustos de la aristocracia serán copiados por los burgueses, quienes también descubren en estos establecimientos una oportunidad de mercado en la que agua y salud se unen a ocio y diversión, germen del turismo moderno en Europa ${ }^{3}$.

\section{La cultura del termalismo}

Durante la etapa prerromana ya se tenía conocimiento de las propiedades curativas de los manantiales y con la llegada de los romanos se perfeccionan las estancias termales. Pero la presencia sueva y visigoda trajo consigo un retroceso del desarrollo cultural previo. Durante la Edad Media este deterioro se acentúa con el abandono definitivo de algunos de los baños romanos, una fase de decadencia que llega hasta el siglo XVIII.

La llegada a la monarquía española de la familia Borbón en el inicio del siglo XVIII vino acompañada de las modas europeas de las casas reales y las élites políticas y cultas, caso de la ingesta de las aguas y de la prác-

2 Entendemos por higienismo la filosofía que defendía la importancia del ambiente en la recuperación y mantenimiento de la salud. Véase Rafael Alcalde, «La introducción y desarrollo del higienismo en España durante el siglo XIX. Precursores, continuadores y marco legal de un proyecto científico y social», Scripta Nova, 50, 1999. http://www.ub.es/geocrit/sn-50.htm.

3 Véase Dominique Jarrassé, «La importancia del termalismo en el nacimiento y desarrollo del turismo en Europa en el siglo XIX», Historia Contemporánea, 25, 2002 (II), pp. 33-49; Marc Boyer, «El turismo en Europa, de la Edad Moderna al siglo XX», Historia Contemporánea, 25, 2002 (II), pp. 8-32; Mihail Moldoveanu (dir.), Ciudades termales en Europa, Lunwerg, Madrid-Barcelona, 2000; Armand Wallon, La Vie quotidienne dans les villes d'eaux : 1850-1914, Comité des travaux historiques et scientifiques, Paris,1994; Allan Williams y Gareth Shaw, Tourism and Economic Development: Western European Experiences, Belhaven Press, London-New York, 1991. 
tica de baños termales como remedios curativos para determinadas enfermedades. Esta nueva moda estaba muy relacionada también con los avances de la química y su aplicación al conocimiento de la composición de las aguas, de la medicina y de la filosofía higienista, aspectos que favorecieron la recuperación de la tradición popular de los baños y el redescubrimiento de los que existían desde la etapa romana. El marqués de la Ensenada, como secretario del Consejo de Castilla, encargó al catedrático de Cirugía y Anatomía de la Universidad de Santiago Pedro Gómez de Bedoya la elaboración de la Historia Universal de las Fuentes Minerales de España (1765, 2 vols.). El mismo autor redacta también ese año el trabajo titulado Descripción de 54 fuentes minerales del Reino de Galicia.

En el caso particular de Galicia, en estos años de recuperación de la tradición de las aguas termales los principales demandantes de las propiedades curativas de los manantiales eran los sectores modestos de las sociedad, que tomaban las aguas y los baños por su convicción de las virtudes medicinales que conllevaban y que habían sido transmitidas en la memoria popular. Ya en la etapa contemporánea aparece de nuevo un momento de esplendor de los baños gallegos que lleva a que entre $1780 \mathrm{y}$ 1874 eclosionen las primeras casas de baños modernas y a que en 1867 se publique la obra Galicia médica: Apuntes para servir al estudio de la geografía médica de Galicia. Si bien es cierto que los episodios de guerra civil en la etapa decimonónica frenaron el proceso de desarrollo del sector, en el censo de balnearios oficiales publicado en la Gaceta de Madrid del 18 de mayo de 1833 aparecen un total de veintiún establecimientos, de los cuales siete eran gallegos; en 1850 el número ascendía a nueve y en 1876, iniciada ya la Restauración, cuando cobra fuerza la explotación de enclaves mineromedicinales en toda España y Europa, eran doce ${ }^{4}$.

${ }^{4}$ Véase Carlos Larrinaga, «Termalismo y turismo en la España del siglo XIX», en Carlos Barciela et al. (eds.), La evolución de la industria turística en España e Italia, Institut Balear d'Economia, Palma de Mallorca, 2011, pp. 569-608; ídem, «A Century of Tourism in Northern Spain: The Development of High-quality Provision between 1815 and 1914», en John K. Walton (ed.), Histories of Tourism: Representation, Identity and Conflict, Channel View Publications, Clevedon-Buffalo-Toronto, 2005, pp. 88-103; ídem, «Le tourisme thermal dans l'Espagne de la Restauration», en Laurent Tissot (dir.), Construction d'une industrie touristique aux 19e et 20e siècles : Perspectives internationales. / Development of a Tourist Industry in the 19th and 20th Centuries: International Perspectives, Alphil, Neuchâtel, 2003, pp. 95-109; ídem, «El turismo en la España del siglo XIX», Historia Contemporánea, 25, 2002 (II), pp. 157-180; Luis Alonso, Margarita Vilar y Elvira Lindoso, El agua bienhechora: El turismo termal en España, 1700-1936, Observatorio Nacional de Termalismo - Ministerio de Agricultura, Alhama de Granada, 2012. 
Desde la desamortización y con la llegada al poder de los progresistas (1854) se lleva a cabo un importante desarrollo de la actividad balnearia al convertirse muchos de estos establecimientos en negocios particulares. Pero para el caso concreto de Galicia la realidad de los establecimientos estaba definida por la precariedad de las instalaciones y de los servicios de hospedaje de las casas de baños. La mayoría de los centros dependían del alojamiento ofertado por un número reducido de fondas modestas, habitaciones alquiladas en las casas de los vecinos y las barracas que se colocaban alrededor de las fuentes. Ofrecían tratamientos de bebida y baños colectivos, todavía no tratamientos individualizados.

La estabilidad política e incluso social que propicia la llegada de la Restauración desde 1874 también favoreció la iniciativa privada, y con un nuevo Reglamento que aparece en este mismo año y la Ley de Aguas de 1879 se insistía en la declaración de utilidad pública de estos establecimientos, aspecto que ya se había iniciado con las normativas previas $(1817,1828$ y 1834) . Esta cobertura legal favoreció la aparición de las primeras instalaciones terapéuticas modernas, hospedajes adecuados a una clientela cada vez más exigente y con accesos acondicionados, lo que también contribuyó al desarrollo de la red de carreteras y ferroviaria, en términos generales ${ }^{6}$. Fue, por lo tanto, a partir del Reglamento de 1874 cuando aumentaron de forma considerable las inversiones en

5 Carlos Larrinaga, «Orígenes del turismo en España. Las aguas de la vida», en Anuario IEHS, Buenos Aires, 2012. Sobre la evolución del turismo en la España contemporánea hasta convertirse en un sector relevante, donde además se evidencia el escaso interés académico prestado al estudio: Carlos Larrinaga y Rafael Vallejo (coords.), Transportes, Servicios y Telecomunicaciones, 24: El Turismo en la Historia de España, 2013.

${ }^{6}$ Un importante número de conexiones por vía férrea a los centros turísticos que eclosionan en la segunda mitad del siglo XIX en Europa fueron construidos bajo el pretexto del tráfico comercial hacia los puertos y los complejos turísticos próximos. Para estudiar la relación existente entre turismo y ferrocarril véase John K. Walton, «Railways and resort development in Victorian England: the case of Silloth», Northern History, 15, 1979, pp. 191-209. Para el caso de España: Rafael Barquín, «El turismo y los primeros ferrocarriles españoles (1855-1900)», Transportes, Servicios y Telecomunicaciones, 24, 2013, pp. 110- 136; Carlos Larrinaga, «Administraciones públicas locales y medios de transporte durante la Restauración: Guipúzcoa», Cuadernos de Historia Contemporánea, n. ${ }^{\circ} 35$, 2013, pp. 113-135. http://dx.doi.org/10.5209/rev_CHCO.2013.v35.42651. Una ampliación de este último tema en ídem, Diputaciones provinciales e infraestructura durante el primer tercio del siglo XX (1900-1936): El caso guipuzcoano, Universidad del País Vasco, Bilbao, 2013, e ídem, «Ferrocarriles y termalismo: la configuración del espacio balneario en el País Vasco», VI Congreso de Historia Ferroviaria, Vitoria-Gasteiz, 5-7 de septiembre de 2012. http://www.docutren.com/congreso_vitoria/propuestas/propuesta1.html. 
los balnearios españoles y, pese a que solo algunos de ellos, los menos, se convirtieron en establecimientos de lujo, al estilo de los mejores de Europa, ninguno llegó a tener una gran repercusión internacional, aunque es evidente que desde este momento despega el termalismo en España como sector turístico de salud y ocio y con demanda fundamentalmente nacional. De las 1.865 fuentes minerales registradas en España en 1877, la zona atlántica septentrional y los Pirineos concentraban la mayor parte ${ }^{7}$.

Pero desde la década de 1880 el aumento de la demanda de los baños de mar y el turismo de ola, donde los enclaves de San Sebastián y Santander ya destacaban como centros turísticos ${ }^{8}$, provocaría una paulatina recesión de la demanda termal estacional. Durante la crisis finisecular y tras el Desastre del 98 los balnearios inician una etapa de cierto estancamiento, un momento en el que también la implantación de la sociedad de masas ya comenzaba a ser una realidad. El paradigma higienista perdía protagonismo ante la difusión del disfrute del ocio y por los mismos avances en bacteriología y la inmunología (Pasteur y Koch), que por extensión produjeron cierta impopularidad de la balneoterapia ${ }^{9}$. Para sobrevivir a la situación los empresarios y gestores de los establecimientos potencian el aspecto lúdico, intentando con ello modernizarse y adaptarse a los nuevos tiempos y gustos sociales. Esta nueva programación traería consigo una segunda etapa de esplendor de los balnearios que llegaría hasta finales de los años 20, etapa en la que dejan de ser simples centros de salud para identificarse con lugares de ocio y veraneo de la burguesía más selecta y los políticos más acreditados.

Cuando se inicia el siglo Xx, de los 249 balnearios españoles que se registran 23 se encontraban en Galicia, la región que más bañistas recibía (entre el 13 y el $17 \%$ del total ${ }^{10}$. La implantación de los gustos bur-

${ }^{7}$ Para consultar una reconstrucción de la evolución de las casas de baños oficiales en el siglo XIX en España, con estimaciones recientes sobre clientela, véase Luis Alonso, Elvira Lindoso y Margarita Vilar, El agua bienhechora..., op.cit.

8 Véase Carlos Larrinaga, «A Century of Tourism in Northern Spain: The Development of High-quality Provision between 1815 and 1914», Walton, J. K. (ed.), Histories of Tourism: Representation, Identity and Conflict, Channel View Publications, Clevedon-Buffalo-Toronto, 2005, pp. 88-103.

${ }^{9}$ Octavio Montserrat, El balneario de Panticosa (1826-1936), Diputación General de Zaragoza, Zaragoza, 1998, p. 231.

${ }_{10}$ Margarita Vilar y Elvira Lindoso, «El sector balneario gallego desde una perspectiva histórica (1780-1935)», Transportes, Servicios y Telecomunicaciones, 10, 2010, 
gueses consolida el sector termal y para el caso gallego destacaron dos enclaves: Mondariz y La Toja ${ }^{11}$. Los clientes de estos lugares de descanso y terapias naturales alternaban los tratamientos hidroterápicos con otras actividades de distensión como excursiones, paseos agrestes, tertulias, sesiones de casinos y musicales. El ocio y la diversión también entraban de lleno en las capas altas de la sociedad gallega desde finales del siglo XIX ${ }^{12}$.

Pero la llegada de la Segunda República fue acogida con desconfianza por las clases altas. A esto habría que sumar el desarrollo de las investigaciones farmacológicas que seguían mermando las creencias terapéuticas de las aguas termales y la implantación definitiva del turismo de ola. Todo ello llevaría a que los balnearios tuvieran que pasar por otra etapa de recesión. La llegada de la Guerra Civil no hizo más que acelerar este proceso involutivo del sector y muchas de las dependencias pasaron a tener una nueva función, hospitales y cuarteles sobre todo; otras cerraron definitivamente.

\section{Galicia en el último cuarto del siglo xIx: la ciudad de Vigo}

Para el caso de España, uno de los estados menos desarrollados de la Europa del momento, los censos de 1860 y 1877 muestran una sociedad preindustrial donde la característica dominante era la ruralización y donde la eclosión de la sociedad de masas todavía no era tan evidente, a lo que habría que sumar el hecho de que la crisis finisecular tendría pésimas consecuencias por el mismo hecho de ser un país poco integrado en la economía internacional.

Dentro del conjunto español Galicia fue un territorio donde prevalecían más las constantes que los cambios. Desde el punto de vista demográfico, durante las últimas décadas del siglo XIX la población gallega era básicamente rural y estaba distribuida con diferente densidad, aunque ya se dejaba ver un mayor crecimiento concentrado en el oeste y en los ayuntamientos

pp. 138-164; p. 155.

11 En los primeros años del siglo xx aparecen estudios como los de Carlos Menéndez y Fernández et al., Guía oficial de las aguas minero-medicinales y establecimientos balnearios de España, Imprenta Hijos de J. A. García, Madrid, 1908.

12 Para tener una perspectiva histórica de los balnearios gallegos véase Margarita Vilar y Elvira Lindoso, «El sector balneario...», op. cit. 
próximos a la costa ${ }^{13}$. En 1887 las ciudades solo contenían el 6,45\% de la población y la continuidad jerárquica interurbana y de pueblos a partir sobre todo de dos referentes, A Coruña y Vigo, definieron la situación. Durante el siglo XIX fue la región española con el menor índice de renta per cápita, lo que provocaría que la emigración a América desde los años de la década de 1880 pasara a ser uno de los aspectos definitorios de la realidad social.

Pero la recuperación económica llegaría sobre todo en el primer tercio del XX, cuando la población pasa de 1,9 millones de habitantes (1900) a 2,2 millones (1936) ${ }^{14}$. Esta inversión de la situación previa se debe a varios factores: en el sector primario tienen lugar la desaparición definitiva del régimen de autoconsumo, la tecnificación del campo y la implantación de la ganadería como eje del sector, lo que llevó a la consolidación de la pequeña explotación campesina (agrarismo y redención foral) y al despegue de la moderna industria naval y conservera a partir de la tradición salazonera, en las que la ría y ciudad de Vigo tuvieron un papel protagonista ${ }^{15}$.

En esta recuperación, la integración en el mercado español mediada por las conexiones ferroviarias de A Coruña (1883) y Vigo (1885) fue imprescindible, junto con la implantación de los servicios urbanos y la paulatina terciarización, aunque el nivel de urbanización todavía fuese bajo. A pesar de que la burguesía y el proletariado eran grupos minoritarios, los núcleos industriales también constituyeron el soporte de una actividad cultural alternativa que llevó a la aparición de casinos, ateneos, sociedades recreativas, círculos de artesanos, periódicos y sociedades de lectura.

Así, y aunque la riqueza de manantiales de la región gallega no se correspondía con un liderazgo termal en el conjunto español, en Galicia también se instaló una explotación balnearia elitista y de lujo durante la

${ }^{13}$ Una tendencia que se aprecia ya desde antes de 1700 y que continuó potenciándose hasta la actualidad. Véase Ofelia Rey, «Migraciones internas y medium-distance en Galicia, siglos XVI-XIX», en Antonio Eiras et al. (eds.), Migraciones internas y medium-distance en la Península Ibérica, 1500-1900, Consellería de Educación y Ordenación Universitaria - Comisión Internacional de Demografía Histórica, Santiago de Compostela, 1994, p. 129.

14 Durante estos años el crecimiento poblacional continuó siendo más rural que urbano, pero el impulso de las ciudades fue evidente desde 1925-1930. Véase José Antonio López, La población de Galicia, 1860-1991, Fundación Caixa Galicia, Santiago de Compostela, 1996.

15 Véase Luis Alonso, «La economía de Galicia, una panorámica, c. 1750-2010», Historia Contemporánea, 42, 2011 (I), pp. 15-66; Xoán Carmona y Jordi Nadal, El empeño industrial de Galicia: 250 años de historia, 1750-2000, A Coruña, Fundación Pedro Barrié de la Maza, 2005, pp. 115-176. 
primera parte del régimen turnista, igual que sucedió en Cantabria, el País Vasco, Guipúzcoa y Cataluña ${ }^{16}$.

\section{Realidad industrial y cultura moderna}

La realidad de la eclosión industrial en la ciudad de Vigo sobre la base del sector conservero del pescado alentó la moderna industrialización de Galicia durante el último cuarto del siglo XIX, tanto por su capacidad de producción como por el efecto de arrastre que tuvo sobre otros sectores, caso de la construcción naval, la pesca en general y otras empresas auxiliares ${ }^{17}$. Durante el último cuarto del siglo XIX el aumento de la población asalariada de la urbe fue considerable, parejo al incremento de la capacidad productiva y al de la implantación de una burguesía financiera. El puerto de Vigo concentraba casi la totalidad de las exportaciones de conservas de las fábricas localizadas en las Rías Bajas y la mayor parte de las importaciones de materias primas y maquinaria exigidas por la industria conservera, la pesca o la construcción naval. La ciudad despegaba como referente económico y se situaba entre los primeros puertos españoles en tráfico de mercancías, configurándose como centro urbano moderno con una aglomeración que se extiende por la ría del mismo nombre ${ }^{18}$. El turismo también fue una nueva actividad en la que los baños de mar tuvieron una representación importante,

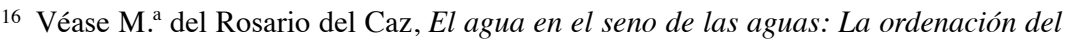
espacio balneario en el Cantábrico, Universidad de Valladolid - Colegio Oficial de Arquitectos de Cantabria, Valladolid, 2000; Carlos Larrinaga, «Nacimiento y evolución del termalismo vasco durante el siglo XIX. El caso de Guipúzcoa», Transportes, Servicios y Telecomunicaciones, 24, 2013, pp. 58-84; para un conocimiento de la sociabilidad de las élites y la función turística desde un estudio comparado de centros balnearios a ambos lados del Atlantico véase el artículo de Carlos Larrinaga y Elisa Pastoriza, «Dos balnearios atlánticos entre el fin de siglo y la crisis del treinta, San Sebastián y Mar de Plata. Un ejercicio comparativo», Historia Contemporánea, 38, 2009, pp. 277-310. Para Cataluña véase Joan Josep Molina, Balnearios, práctica termal y orígenes del turismo en la Catalunya contemporánea (1850-1950), Astro Uno, Barcelona, 2008. Para el caso de Galicia disponemos de la obra de Luis Alonso, Elvira Lindoso y Margarita Vilar O lecer das augas: Historia dos balnearios de Galicia, 1700-1936, Galaxia, Vigo, 2011.

17 Jesús Giráldez, Crecimiento y transformación del sector pesquero gallego (1880-1936), Ministerio de Agricultura, Pesca y Alimentación, Madrid, 1996.

${ }_{18}$ Para observar una transformación similar en el caso de Bilbao. Véase Susana Serrano, «El puerto de Bilbao: poder local y transformaciones urbanas (1876-1936)», Itsas Memoria, 7, 2012,pp. 229-248.http://www.untzimuseoa.net/images/itsas_memoria_07/12_ susanaserrano_abad.pdf. 
lo que nos lleva a pensar en una interrelación y complementariedad entre la actividad pesquera e industrial de la urbe y el desarrollo del turismo (veraneo) como nuevo nicho de mercado, basado en la explotación de las propiedades terapéuticas de las aguas del mar, otra forma de aproximación a la naturaleza, igual que ocurrió en Brighton o Whitby ${ }^{19}$. Es el germen del turismo de ola y sol que ya comenzaba a diferenciar las aguas cálidas de las Rías Bajas de las aguas frías del norte de la región ${ }^{20}$.

Los edificios con fachadas de granito autóctono, que a modo de telón escénico se extendieron por las principales calles y avenidas articuladas entre sí y con el área suburbana a través de red tranviaria desde $1914^{21}$, y la proliferación arquitectónica de los nuevos espacios (muelles e instalaciones portuarias en terrenos ganados al mar) y bulevares burgueses con residencias eclécticas (Arenal, Policarpo Sanz, Elduayen, García Barbón, Urzáiz, Colón, Montero Ríos, Príncipe, la Puerta del Sol y la plaza de Compostela sobre todo), junto con una red de industrias y de barrios obreros a las afueras de la ciudad y el abandono paulatino del centro histórico, vendrían a ser el reflejo del auge económico que transformó el núcleo olívico en una ciudad moderna, aunque «irregular, varia y pintoresca en su estructura material; hidalga y progresiva en su espíritu, [con] el atractivo y el encanto de lo vario, de lo desigual, de lo irregular, de lo complejo ${ }^{22} \gg$.

\section{Ocio y turismo}

Con el nuevo siglo aparece también una concepción más moderna y profesional del periodismo, además de la prensa especializada. El público entraba en contacto con la publicidad ilustrada por medio de revistas, car-

19 Para tener una visión de la complementariedad entre puertos y complejos turísticos en distintas localidades de Gran Bretaña y Europa véase Peter Borsay y John K. Walton (eds.), Resort and Port: European Seaside Towns since 1700, Channel View Publications, Bristol-Buffalo-Toronto, 2011.

20 Para consultar una aproximación al turismo de ola en España: Carlos Larrinaga, «De las playas frías a las playas templadas: la meridionalización y popularización del turismo de ola en España en el siglo XX», 1.er Congreso Latinoamericano de Historia Económica y 4.as Jornadas Uruguayas de Historia Económica (CLADHE I - IV JUHE), Montevideo, 5-7 de diciembre de 2007.

${ }^{21}$ Para estudiar la historia de los tranvías de Vigo véase Antonio Giráldez, Recordando los tranvías de Vigo, Diputación Provincial de Pontevedra, Vigo, 2005.

${ }^{22}$ Herberto Blanco, «Descripción de las bellezas de Vigo y sus alrededores», Mondariz. Suplemento a La Temporada, 20.5.1916, pp. 260-267. 
teles, programas de espectáculos, catálogos, tarjetas postales y de felicitación e invitaciones, además de las viñetas. Para el caso concreto de Vigo destaca la aparición en 1909 de la revista ilustrada Vida Gallega, con reportajes que van desde la cultura popular hasta la emigración, pasando por espectáculos, deportes, excursiones y estancias en Mondariz de políticos y otros personajes público.

La ciudad adquiere capacidad de intermediación comercial y desde finales del siglo XIX se consolida en ella un estilo de vida con mercados, cafés, cines, restaurantes, hoteles y escaparates de comercios relacionados con la alimentación (ultramarinos), vestido, calzado y otras mercerías que definían la estética urbana. Entre los cafés, los lugares de sociabilidad por excelencia, estaban el Méndez Núñez, el Suizo, el Colón, el Universal y el Café Nuevo. Entre los restaurantes eran conocidos La Fama y La Cueva y entre las sociedades de recreo estaban La Oliva, La Tertulia y el Círculo Mercantil, donde se celebraban festejos y bailes de sociedad. Además del teatro, el cine también comienza a tener difusión con la sala Tamberlick, el Royalty y el Odeón. La promoción turística de la ciudad contaba con hoteles como el Continental, el Universal y el Moderno ${ }^{23}$. Con respecto a la moda, ya cuando se inicia la segunda mitad del siglo se tiene constancia de la difusión en la ciudad de la moda inglesa y de París. Poco a poco se produce el abandono de la indumentaria tradicional gallega, que en estos años convive con las nuevas tendencias. Desde finales del siglo XIX en el comercio local destaca la figura de Teodoro Gómez Curieses, que introdujo las nuevas tendencias cuando el 11 de abril de 1897 inauguró La Villa de París, en la Puerta del Sol, un comercio con toda clase de artículos textiles que alcanzó popularidad incluso entre los turistas.

En sus inicios el automóvil era elitista, utilizado por los visitantes y turistas más pudientes y algún profesional liberal. La familia conservera Curbera Hernández adquirió el automóvil más antiguo de la provincia: un Renault 2 cilindros y 10 caballos que contaba con cuatro asientos. Cuando llega el año 1910 Vigo ya sumaba aproximadamente un centenar de automóviles. Comenzaban también a funcionar los primeros taxis, que pronto se convirtieron en competencia para los carruajes y coches de caballos que todavía circulaban por la ciudad.

${ }^{23}$ Para observar los cambios en la sociedad de masas ante el fenómeno de la modernidad véase Jorge Uría, «Cultura popular y actividades recreativas: la Restauración», en ídem (coord.), La cultura popular en la España contemporánea: Doce estudios, Biblioteca Nueva, Madrid, 2003, pp. 77-107. 


\section{Los baños de mar y el turismo de ola y sol}

La práctica de los baños de mar comienza en España por los años 1830, unas décadas después de que apareciera en la parte noroccidental del continente $^{24}$. De hecho, el Cantábrico oriental está considerado el primer espacio turístico de la costa de España, donde destacaron desde la primera mitad del siglo XIX los enclaves de San Sebastián y Santander. A partir de aquí eclosionan también los enclaves de Cádiz y Málaga con la pretensión de semejarse a los ejemplos emblemáticos de Niza y Cannes en la costa mediterránea francesa. Para el caso concreto de España, en la difusión de los baños de mar, desde el norte sobre todo, había tenido un papel importante la misma Isabel II. A causa de la enfermedad cutánea que padecía los facultativos de palacio le recomendaron tomar baños de mar desde niña como remedio natural para disminuir las inflamaciones de la piel. Al parecer, las playas que más le agradaban eran las del norte, donde solía pasar los períodos estivales. Esta práctica llegó a convertirla en una afición que también mantuvieron sus sucesores, igual que en otras casas reales europeas, lo que contribuiría a la difusión de la moda del veraneo entre las elites.

Los turistas extranjeros comenzaron a ser objetivos de los Gobiernos en la década de 1870, igual que sucede en Suiza y Francia. Las campañas para atraer a los visitantes se fueron potenciando desde entonces y en 1911 se crea la Comisaría Real de Turismo, antes incluso que en Francia, Italia y Suiza; a partir de este momento la costa mediterránea inicia su proyección como destino vacacional de las clases medias europeas. Aunque en un primer momento el bañismo fue una costumbre elitista como otra forma de aproximación a la naturaleza basada en las propieda-

${ }^{24}$ Según John K. Walton, los baños de ola nacieron en Gran Bretaña en el siglo XVIII y a partir de aquí se convirtieron en norma cultural, por Europa occidental sobre todo. Brighton vendría a ser el modelo que se impuso a partir de 1730: John K. Walton, «Consuming the Beach: Seaside Resort and Culture of Tourism in England and Spain from the 1840s to the 1930s», en Shelley Baranowski y Ellen Furlough (eds.), Being Elsewhere: Tourism, Consumer Culture and Identity in Modern Europe and North America, University of Michigan Press, 2001, pp. 272-298. Para tener un conocimiento de estos espacios marítimos en general véase Fred Gray, Designing the Seaside: Architecture, Society and Nature, Reaktion Books, London, 2006. Para el caso concreto de España, Alet Valero, «El turismo de playa en España entre 1850 y 1950 (creación, madurez y crisis)», en Francis Fourneau y Andrés M. García (dirs.), Desarrollo regional y crisis del turismo en Andalucía, Instituto de Estudios

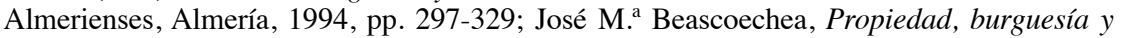
territorio: La conformación urbana de Getxo en la ría de Bilbao (1850-1900), cap. 6: «Los nuevos modos sociales: el veraneo», Universidad del País Vasco, Bilbao, 2007, pp. 177-190. 
des terapéuticas del agua marina, que también se revalorizan con el higienismo ${ }^{25}$, pronto se extendió entre la población con las primeras casas de baños modestas. Del interés económico que subyacía a la promoción de estos establecimientos en las poblaciones ribereñas surgirían iniciativas empresariales para la explotación del sector.

Las primeras casas de baños se adentraban en las playas a modo de palafitos elevados sobre pilares de madera. Sabemos que la primera de ellas en la ciudad de Vigo la construyó Norberto Velázquez Moreno a mediados del XIX y estaba situada en el extremo de la Ribera del Berbés. La puesta en escena de la actividad era todo un «ritual» sometido al pudor de la moral católica: separados ambos sexos por una cuerda que dividía la zona de playa, los bañistas se acondicionaban para el baño dentro de las casetas provistas de ruedas que se deslizaban hasta el borde de la playa sobre unos tablones a modo de raíles. Una vez que se encontraba en la orilla, o incluso ya dentro del agua, el o la bañista se introducía en el mar, donde se sujetaba a otras cuerdas previamente colocadas por el servicio de la casa. La escena se repetía en sentido inverso. Ya vestidos de calle los protagonistas evitaban la exposición directa al sol; la tez morena todavía era algo «mal visto», asociado a los campesinos y marineros ${ }^{26}$.

A continuación Cándido Soto Castro, emigrante retornado, inaugura el 10 de julio de 1876 en la playa de la Batería (A Laxe) La Iniciadora, a partir de un proyecto del arquitecto local Jenaro de la Fuente. Era un inmueble más consistente, con pilares de sillería y con una superficie de 265 metros cuadrados. Pasó a ser un lugar muy frecuentado por los grupos acomodados, asiduos a los conciertos de música y baile y a las sesiones de gimnasia que ofrecía. Estuvo en funcionamiento durante dos décadas, período en el que también pasó por dos reformas de ampliación, en 1878, cuando se llega a las 78 habitaciones y se pasa a disponer también de un restaurante, y en 1885, momento en el que se construye una sala de billar en el segundo piso y habitaciones con acceso directo

25 Alain Corbin, El territorio del vacío: Occidente y la invención de la playa (1750-1840), Mondadori, Barcelona, 1993, p. 94.

${ }^{26}$ La diseñadora de moda francesa Coco Chanel aprovechó el bronceado que se adquiría en las estancias de playa para introducir en la década de 1920 los primeros trajes de baños femeninos, lo que nos lleva a pensar que la liberación del cuerpo también estuvo detrás de toda esta proyección del veraneo en Europa. Sasha D. Pack, «Tourism, Modernisation and Difference: A Twentieth-Century Spanish Paradigm», documento de trabajo del Seminario de Historia del Instituto Universitario Ortega y Gasset, curso 2006-2007 (26.4.2007), p. 19. http://www.ucm.es/data/cont/docs/297-2013-07-29-3-07.pdf. 
al mar ${ }^{27}$. Pero las obras del malecón desde A Laxe a la Ribera del Berbés en 1896, necesarias para continuar con el crecimiento de la actividad portuaria, llevaron a la desaparición de esta casa de baños. En 1903 el mismo indiano solicita la reconstrucción de La Iniciadora, de nuevo a partir de un proyecto de Jenaro de la Fuente. Esta se inaugura un año después, en 1904, definiéndose ya como un inmueble ecléctico singularizado con elementos neomoriscos; disponía de un hotel en el segundo piso ${ }^{28}$.

Las últimas casas de baños de la Ribera del Berbés se instalaron en las playas de San Francisco y de San Sebastián a comienzos del siglo Xx, pero a partir de los años treinta, con la liberación del cuerpo y el fomento de las competiciones deportivas, estos establecimientos comenzaron a caer en desuso ${ }^{29}$.

Lo dicho hasta aquí nos lleva a pensar que a comienzos del siglo XX Vigo se definía ya como una ciudad moderna, al estilo de Brighton desde hacía casi un siglo ${ }^{30} \mathrm{o}$ de Biarritz, repleta de calles que se precipitaban hacia la ría y donde lo rural y provinciano se mezclaba con lo moderno y europeo transmitido por los pasajeros de los barcos que atracaban en el puerto. De esta visión de contrastes como singularidad queda constancia en el testimonio de la viajera inglesa Catherine Gasquoi:

In Vigo there was apparently no idleness (...). Life was everywhere. And this impression of active occupation (...) was increased when we made a brief visit to the fish-and-fruit market, which is held each morning along the quay, in the center of the town (...). It is the most animated scene I have ever witnessed (...). Outside the market, on the steep flight of steps and roadways which lead up into the town, wares were being sold (...).

27 Jaime Garrido, «Casas de baños», en VV. AA., Historias de las Rías, vol. II, Faro de Vigo - Fundación Caixa Galicia, Vigo, 2000, pp. 713-728; p. 721.

${ }_{28}$ Faro de Vigo, 15.5.1904.

29 Margarita Barral, «Los nuevos gustos colectivos y la sociedad a comienzos del siglo XX», en ídem, (coord.), Historia de Vigo, Faro de Vigo - Fundación Caixa Galicia, OviedoVigo, 2005, pp. 301-312.

30 Para el caso del desarrollo de Brighton como núcleo pesquero pionero en el desarrollo del turismo balneario desde la década de 1730 hasta la actualidad, en el que además queda patente tanto la complejidad de las relaciones entre ambos aspectos como su convivencia e interrelación a largo plazo, véase Frey Gray, «Three Views of Brighton as Port and Resort», in Peter Borsay y John K. Walton (eds.), Resort and Port..., op. cit., pp. 66-85. Para tener un conocimiento del desarrollo de Brighton como centro turístico e influyente en el occidente europeo en los siglos XVIII y XIX, Sue Berry, Georgian Brighton, The History Press Limited, Chichester, 2005. 
All that was active and modern appeared as an addition to what was old; it did not seem to belong here (...). In Vigo (...) I was finding new tracts of discoveries, as it were, stirring into life fresh feelings and points of view that were unexpected to me in this land of romance (...). I saw señoras and señoritas garbed in hideous Paris and English fashions, and men dressed in Harris tweeds, walking in the same streets with the fisherfolk in their ancient, picturesque costumes.

Along the Alameda, the wide promenade, smoothly asphalted and of perfect surface, oxen with huge, branching horns were moving slowly. They carried the stones for the houses that were being built in long wooden carts of the most primitive pattern (...). And on the same promenade, where these bullock-carts were passing, the automobiles waited to take us to Mondariz ${ }^{31}$.

Este interesante testimonio muestra cómo en Vigo la actividad pesquera tradicional y el mundo industrial que eclosionaba se mezclaban con los nuevos negocios de ocio y placer que anunciaban los inicios del turismo moderno en la ciudad y en la región, igual que ocurría en otros lugares de similares características y condiciones, caso de Yarmonth, en la provincia de Nueva Escocia (Canadá) ${ }^{32}$. Además, la identidad local y provincial, en el sentido cultural, etnográfico, se sumó como valor añadido a la pretendida difusión del nation-building que venía de la mano de la cultura política liberal, la difusión e implantación de una identidad nacional hegemónica que asegurase el triunfo de liberalismo dentro del conjunto europeo $^{33}$. En las pretensiones regeneracionistas de Alfonso XIII también se incluía la difusión de un sector turístico que diera a conocer la riqueza natural de España y su grado de desarrollo industrial e integración económica internacional ${ }^{34}$.

${ }^{31}$ Catherine Gasquoine, Spain Revisited: A Summer Holiday in Galicia, Stanley Paul \& Co, London, 1911, pp. 30-33.

32 Véase K. Baedeker, Great Britain: Handbook for Travellers, Leipzig, 1894, pp. 14-15 y 448-449, citado en Peter Borsay y John K. Walton, «Introduction: The ResortPort Relationship», en ídem (eds.), Resort and Port..., op. cit., pp. 1-16; p. 2.

${ }^{33}$ Para consultar una aproximación de la difusión del nation-building en Galicia en el siglo XIX véase Margarita Barral, A visita de Isabel II a Galicia en 1858. Monarquía e provincialismo ao servizo da nacionalización, Sotelo Blanco, Santiago de Compostela, 2012.

34 Javier Moreno, «Alfonso el Regenerador. Monarquía escénica e imaginario nacionalista español en perspectiva comparada (1902-1913)», Hispania, 244, 2013, pp. 319-348; pp. 335-336. 


\section{El balneario de Mondariz}

Tras la división provincial del estado español en 1833 se lleva a cabo la división de los ayuntamientos con arreglo al RD de 23 de junio de 1835. En este momento Mondariz-Balneario todavía no existía y sus territorios formaban parte de la parroquia de Santa Eulalia de Mondariz, con alrededor de medio centenar de casas. Desde 1904 el enclave pasa a individualizarse en la parroquia de Troncoso, una extensión de 2,4 kilómetros cuadrados que se disgregaba de los territorios del conjunto de la de Santa Eulalia, «con miserables viviendas» y que desde los años de la década de 1890 se convierte en «un pueblo con edificaciones modernas, alegre y bonito» ${ }^{35}$. Dos decenios después, el 30 de noviembre de 1924, el general Primo de Rivera, cliente del Balneario y definido en $L a$ Temporada como «el salvador de España» ${ }^{36}$, le concede la distinción de ayuntamiento independiente con la denominación de Mondariz-Balneario, en referencia al poderío económico que adquiriera la explotación de las aguas termales desde los años 1870 bajo el patrocinio de la familia Peinador, como veremos.

\section{El origen empresarial de Aguas de Mondariz: la familia Peinador}

Desde el siglo XI se tenía conocimiento de la existencia de una zona de baños minerales en un espacio conocido como Troncoso, pero se ignora si es o no de origen romano y si fue explotada con anterioridad al siglo XIX. Cuando llega el año 1864 el párroco Domingo Blanco, con el apoyo del obispo de la diócesis de Tui, Telmo Maceira, se interesa por el manantial y encarga el análisis de las aguas al químico Antonio Casares y al médico Maximino Teijeiro, ambos catedráticos de la Universidad de Santiago. El resultado fue una clasificación de aquellas como bicarbonatadas, sódicas, ferruginosas y alcalinas, lo que las hace ocupar el cuarto lugar entre las más mineralizadas de este tipo en el continente europeo, detrás de las de Vichy, Vidago y Rodna ${ }^{37}$.

35 Pío L. Cuiñas, «Mondariz», Galicia Moderna, 1897, s. p.

${ }^{36}$ La Temporada en Mondariz, 5.8.1928, portada.

37 Luis Alonso, Elvira Lindoso y Margarita Vilar, «Mondariz: a Belle Époque viva no tempo», ídem, O lecer das augas..., op. cit., pp. 397-437; pp. 399-401. 


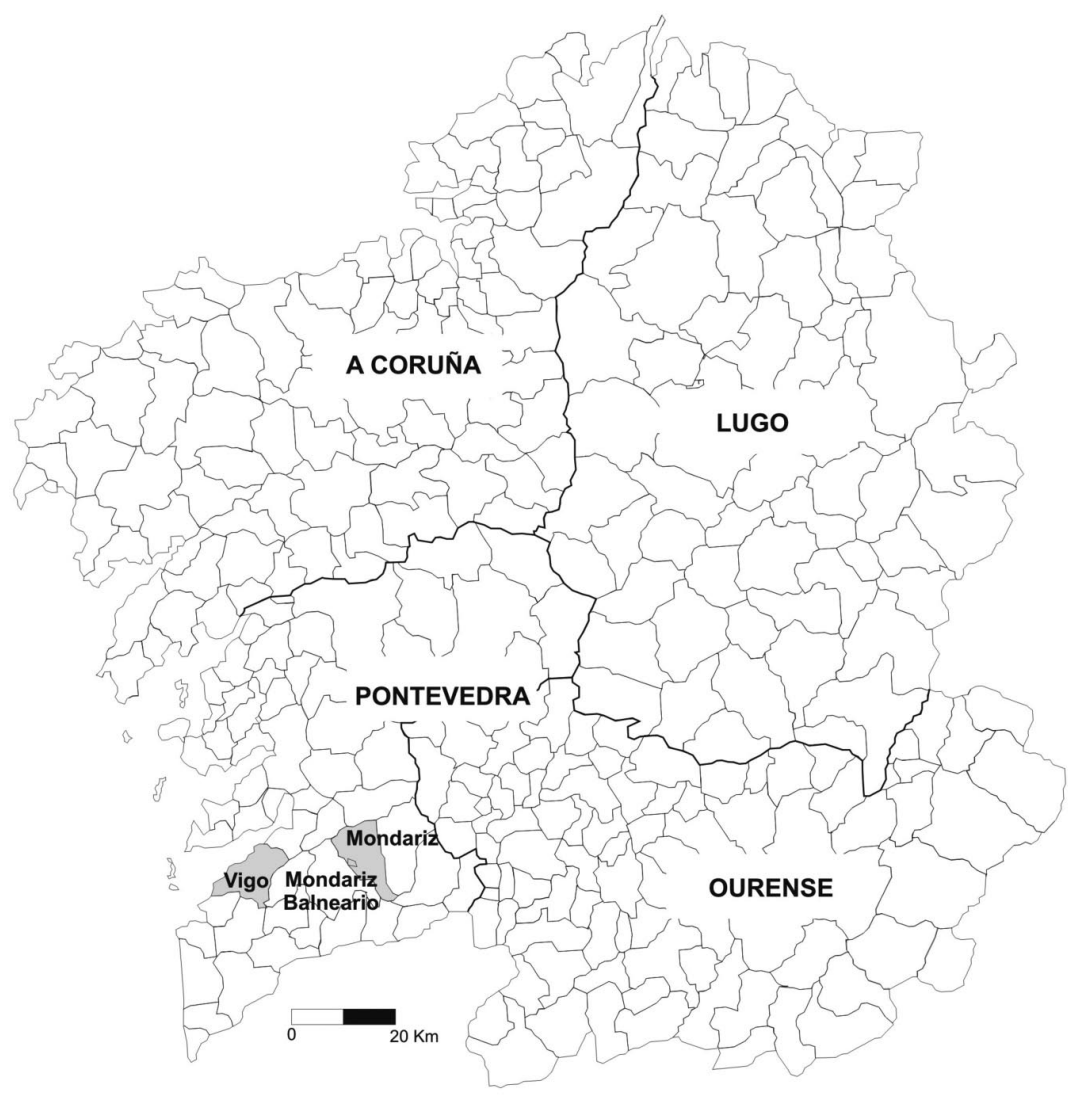

\section{Mapa 1}

Mapa municipal de Galicia en el que se señalan los ayuntamientos de Vigo, Mondariz y Mondariz-Balneario, en la provincia de Pontevedra.

Fuente: Elaboración propia.

Desde este momento el mismo cura se encarga del mantenimiento del manantial gracias a las limosnas de los agüistas; y se facilitó el acceso a él tras la expropiación de los terrenos necesarios por parte del consistorio. Tras el fallecimiento del religioso en febrero de 1886 el deterioro del manantial se acentúa poco a poco. Pero ya en los años 70 un médico de 
Tui, Sabino Enrique Peinador Vela, inspeccionaba la zona acompañado de un ingeniero de minas, Isidoro Sebastián Buceta Solla, con la pretensión de localizar manantiales minerales ${ }^{38}$. Se toparon con el de Chan da Gándara, a un kilómetro de distancia de Mondariz, con aguas similares a las de Troncoso. Enrique Peinador adquiere los terrenos donde se encontraba el manantial y a partir de este momento, junto con su madre y su hermano Ramón, abogado, inicia la trayectoria de la empresa familiar destinada a la explotación de las aguas de Mondariz. Con fecha del 16 de junio de 1873 el Gobierno republicano declara de utilidad pública el manantial. En ese mismo verano se acondiciona la fuente para su uso y, como para tal fin era necesario nombrar un director médico, este fue un hermano del poeta gallego Eduardo Pondal, Isidro Pondal, que mantuvo el cargo hasta su jubilación en $1918^{39}$. En diciembre de 1888 la regente M. ${ }^{a}$ Cristina distingue Aguas de Mondariz como proveedor oficial de la Casa Real.

Entre las pretensiones de la familia Peinador estaba incluso la suspensión de la explotación pública que se hacía de la fuente de Troncoso, como propiedad comunal que era, con el fin de adquirirla y conectar ambos manantiales. Tales pretensiones llevaron a que se abriera un proceso judicial que entre demandas, resoluciones y recursos se prolongaría hasta el año 1888, momento en el que el jurisconsulto y político reconocido de la Restauración Eugenio Montero Ríos ${ }^{40}$ consigue desde el Consejo de Estado una sentencia favorable a los hermanos Peinador. En el año 1905 la familia reafirma su victoria a través de una nueva sentencia, esta vez de la Audiencia Territorial de A Coruña, en la que se les concedía de forma definitiva la propiedad de la fuente de Troncoso.

La explotación comercial del manantial se inicia por tanto en los años setenta del siglo XIX, con el embotellado del producto para dispensar el preciado líquido como bebida. Por este tiempo los escaparates del desarrollo por excelencia del mundo occidental eran las exposiciones inter-

38 Para consultar una aproximación a la biografía de este médico-empresario véase Luis Domínguez y Xosé Ramón Quintana, «Enrique Peinador Vela (1874-1917)», en Xoán Carmona (coord.), Empresarios de Galicia, vol. 1, Fundación Caixa Galicia, Santiago de Compostela, 2006, pp. 182-203.

39 Desde la RO de 29 de julio de 1816, que desarrolla la Ley de Aguas médico-medicinales, era obligatorio tener un médico director en los balnearios oficiales, que formaba parte de un cuerpo facultativo al que se accedía por oposición.

40 Para consultar un estudio de la figura del jurisconsulto gallego Eugenio Montero Ríos véase Margarita Barral, Montero Ríos y Compostela: un feudo clientelar, Ronsel, Barcelona, 2007. 
nacionales o universales, adonde también llegaron las botellas verdes del Agua de Mondariz ${ }^{41}$.

A partir de finales de la década de 1870 es cuando la familia Peinador amplía su empresa con la construcción de una casa de baños que comienza a funcionar en 1880. Pero la continua afluencia de enfermos, de condición acomodada la mayoría, no tardaría en superar la capacidad de estas instalaciones, que no posibilitaban más de cincuenta baños diarios. Esta situación propició la construcción en 1889 de dos hoteles en los terrenos adyacentes, destinados a alojar a los clientes de élite que demandaban ya mayores prestaciones. A este tipo de alojamiento habría que sumar algunas plazas que ofrecían los vecinos del lugar.

Viendo las posibilidades del negocio Enrique Peinador continúa en su empeño de hacer medrar la empresa y convertirla en un balneario de lujo, lo que lo lleva a promocionar cuatro grandes edificios que constituirían realmente el complejo termal de lujo que deseaba construir a partir de finales de la década de los 90: el Gran Hotel, la Fuente de la Gándara y la Planta Embotelladora, el Edificio de la Baranda y el Sanatorio. La Fuente de Troncoso se integra en el complejo en el año 1908, tras haber ganado el pleito que concedía la propiedad a la familia Peinador (1905). Es decir, se inicia una planificación espacial con voluntad de ordenamiento que llevó a la conformación definitiva de espacio balneario:

- El Gran Hotel, de estilo ecléctico afrancesado con la singularidad especial que le proporciona el granito gallego, también es obra del arquitecto Jenaro de la Fuente; se inicia en 1893 y fue inaugurado en 1898, con una capacidad para 500 huéspedes. El edificio contaba con una escalera de honor de tipo imperial y con una sala de fiestas y de comedor con capacidad para 800 comensales. El proyecto final del inmueble resolvió las inquietudes de los Peinador: incluir el balneario de Mondariz en el círculo de los grandes centros termales españoles y europeos, con las exigencias de higiene, confort y lujo que ello implicaba, iluminación eléctrica y servicio telegráfico. Además, el proyecto estuvo vinculado a la adquisición de la finca colindante conocida como de Pías, que fue acondicionada para actividades productivas, lúdicas y culturales, caso del museo etnográfico-arqueológico.

${ }^{41}$ Luis Alonso, Elvira Lindoso y Margarita Vilar, «Mondariz: a Belle Époque..., op. cit., p. 407. 
- La Fuente de la Gándara y la Planta Embotelladora (tras la demolición de la antigua casa de baños) fueron construidas en 1914, el Pasaje de la Baranda entre 1915 y 1926 (donde se unían las funciones de salud y ocio al albergar servicios médicos y de análisis clínicos con servicios comerciales) y el Hotel Sanatorio se inicia en 1909. Fueron construcciones eclécticas de orientación clasicista proyectadas por el arquitecto y urbanista gallego Antonio Pala$\operatorname{cios}^{42}$. Aunque el proyecto del Sanatorio para artríticos nunca llegó a concluirse, la familia pretendía que fuese una prolongación de la Universidad, donde reconocidos facultativos españoles y extranjeros ejercieran la docencia, «haciendo de Mondariz la Compostela del enfermo, encontrada y ungida por la ciencia ${ }^{43}$.

En 1899 se edita el Album-Guía de Mondariz y en ese momento también comienza la etapa de mayor esplendor del balneario, el primer tercio del siglo XX, con una estimación de clientes de alrededor de 3.000 por temporada. La publicación mensual La Temporada en Mondariz (1889-1931) se publica entre mayo y septiembre, siendo la primera experiencia de prensa empresarial en Galicia; se distribuía de forma gratuita a los clientes y entre la intelectualidad gallega. Junto con la revista Mondariz. Suplemento a La Temporada, que editaba siete números en los meses de verano, era el órgano directo encargado de publicitar el complejo termal-turístico, además de fomentar la identidad regional.

En 1906 aparece la primera publicación del centro en inglés desde el Liceo Club de Londres, A Monograph of Mondariz, bajo la dirección de Rachel Challice. Tras su paso por el balneario en 1911 la viajera inglesa Catherine Gasquoine opinaba que

The way to enjoy her [Mondariz] is to follow the example of the Spaniards who visit the place so often, and to make the most of simple pleasures. To walk in the gardens or the pine-woods, to drink the healthgiving waters, to make purchases in the kiosks, with tempting wares from Madrid, to take picnic on donkeys to the faming estate of Pias; to listen to music, to dance, to talk, - it is to these pastimes that the days at Mondariz

42 Para consultar un estudio arquitectónico del complejo del balneario de Mondariz dentro de la cultura gallega de finales del siglo XIX, además de obtener un conocimiento de todos los aspecto que interactuaron en la creación de la villa balnearia Mondariz-Balneario, véase Yolanda Pérez, El Balneario de Mondariz: La creación de un lugar (1873-1931), tesis doctoral, Servizo de Publicacións da Universidade de Santiago, Santiago de Compostela, 2005.

${ }^{43}$ La Temporada en Mondariz, número extraordinario, 1.6.1927, p. 11. 
are given, and the pleasures is in the emotions to which these enjoyments minister. These are of the finest, and the only way to care for Mondariz as she deserves to be cared for is to pass your days as in joyous courtship ${ }^{44}$.

\section{De cómo se llegaba a Mondariz y se vivía en el lugar}

A finales del siglo XIX el acceso hacia el interior de la provincia de Pontevedra seguía siendo muy precario. El ayuntamiento de Mondariz estaba unido a la cabecera del partido judicial, Ponteareas, por un camino vecinal de casi nueve kilómetros y aconsejado solo para tránsito diurno por sus pésimas condiciones. Desde el puerto de Vigo los viajeros podían ir en tren hasta $\mathrm{O}$ Porriño, la estación ferroviaria más cercana al balneario, a 20 kilómetros, o ir directamente hasta el balneario en carruaje, necesitando para ello un tiempo aproximado de tres horas. Los viajeros procedentes de Madrid debían disponer de al menos dos días para realizar el viaje, pudiendo elegir entre dos rutas hasta O Porriño: la línea norte del ferrocarril Madrid - Venta de Baños - Monforte y la línea de Portugal que comunicaba Madrid - Ciudad Real - Badajoz - Valença do Minho, alternativa que adquirió auge a partir de la inauguración del puente internacional sobre el río Miño en Tui el 25 de marzo de 1886. La afluencia de portugueses en Mondariz llegó a ser tan destacada que en algún momento parecía Mozambique ${ }^{45}$. También existía un servicio de automóviles para los más adinerados y a partir de 1908 los hermanos Peinador adquirieron una flota de ocho de la casa alemana Sag Gaggenau para trasladar a sus clientes más destacados. En 1912 se publica Mondariz-Vigo-Santiago. Guía del Turista, donde se dice que

Mondariz es punto forzoso de etapa para los viajeros ingleses, según se determina en los itinerarios de la Boot Line. Desde hace años los vapores de esta importante compañía naviera de Liverpool, en sus viajes de turismo, tocan tres veces al mes en Vigo y vuelven allí á recoger los pasajeros (...).

En el referido puerto desembarcan también muchos viajeros de América y de la Europa central con el doble objeto de reposar su salud en Mondariz y de visitar la hermosa comarca pontevedresa. En el mismo caso se encuentra Portugal (...), desde donde acuden todos los años (...) innumerables bañistas. Y, por último, su Gran Hotel es en la región uno de los que pueden ofrecer á las personas distinguidas al-

\footnotetext{
44 Catherine Gasquoine, Spain Revisited..., op. cit., p. 66.

45 Pio L. Cuiñas, «Mondariz», Galicia Moderna, 1.10.1897, s. p.
} 
bergue cómodo y elegante, mesa excelente, facilidades para recorrer el país y condiciones de lujo y de confort que le igualan con los Palaces más acreditados del mundo ${ }^{46}$.

Mondariz se convertía así en una cita veraniega de las clases más acomodadas. Desde miembros de la realeza como la infanta Isabel, primogénita de la reina Isabel II, o el sultán de Marruecos entre 1908 y 1912, Abd al-Hafid, y otros jefes políticos y personajes adinerados de la península y Europa estuvieron en el Balneario de Mondariz. En la transición del siglo XIX al XX la visita asidua de personajes de la política central como Emilio Castelar, Montero Ríos, Melquíades Álvarez o González Besada, entre otros, fomentaron el desarrollo de las redes de contactos en el ambiente de los amigos políticos y de las redes clientelares que definieron el turnismo. Entre los asiduos al balneario también destacaban personajes de la cultura como Emilia Pardo Bazán ${ }^{47}$ a ojos de quien para «conocer, sorprender en su vida diaria a los escritores españoles de renombre [y] a los políticos de talla: a Mondariz» ${ }^{48}$.

La familia Peinador también se convirtió en patrocinadora de la cultura autóctona y del movimiento galleguista. A Enrique Peinador Vela le coincidió la época del Rexurdimento, con protagonistas como Rosalía de Castro, Curros Enríquez o Lamas Carvajal, y ejerció el mecenazgo con el pintor Ovidio Murguía, hijo de Rosalía y Manuel Murguía. Enrique Peinador Lines continuó dando cobertura tanto al regionalismo gallego como a la identidad nacional desde comienzos del siglo XX, confirmando así el hecho de que el proceso de nacionalización del Estado liberal español tuvo más éxito en el plano de la actividad intelectual que a través de las políticas de la memoria promovidas por las instituciones públicas ${ }^{49}$. Con respecto al mecenazgo, lo ejerció sobre el Seminario de Estudios Gallegos y con la creación de los Premios Mondariz para el fomento de estudios sobre Galicia. Sobre la promoción de la cultura gallega también destacan

${ }^{46}$ Mondariz-Vigo-Santiago. Guía del Turista, Sucesores de Rivadeneyra, Madrid, 1912 , pp. 5 y 6.

47 Véase Yolanda Pérez, «La escritora en el Balneario: Emilia Pardo Bazán», La Tribuna, 4, 2006, pp. 271-290.

48 La Temporada en Mondariz, número extraordinario, 1.6.1927, p. 7. Para estudiar el vínculo existente entre la política de la Restauración y el desarrollo del turismo balneario en Galicia véase Margarita Vilar, «Balnearios, intereses políticos y desarrollo turístico», Cuadernos de Historia Contemporánea, 33, 2011, pp. 163-185.

49 Ramón Villares, «Nacionalismo e Historia en la España del siglo XIX», en VV. AA., Nacionalismo e Historia, Universidad de Valladolid, Valladolid, 2005, pp. 87-110; p. 109. 
en La Temporada los artículos referidos al patrimonio ${ }^{50}$, la sección de gallegos y gallegas ilustres (literatos e industriales) ${ }^{51}$, artículos sobre la gaita y la música gallegas ${ }^{52}$, la celebración en sus instalaciones del acto de entrada de Ramón Cabanillas y Antonio Rey Soto en la Real Academia Gallega en septiembre de $1920^{53}$ y el mismo hecho de que Castelao colaborase en la edición de logotipos para las botellas de Aguas de Mondariz.

\section{El tranvía Vigo-Mondariz, una realidad inconclusa}

La familia Peinador y la misma burguesía local eran conscientes de la importancia que tendría el mismo hecho de comunicar por vía férrea el enclave termal con el puerto de Vigo. Esta situación de partida llevó a que ya desde 1887 existiesen referencias a la creación de la línea tranviaria Vigo-Mondariz, aunque solo llegó a ser una realidad el tramo de 18 kilómetros entre Vigo y O Porriño desde $1920^{54}$.

La primera victoria del proyecto fue la aprobación de la línea en junio de 1895, aunque desde este momento la existencia de intereses privados que pretendían modificaciones del trazado de la línea fueron acumulando retrasos hasta que en 1902 Eugenio Montero Villegas, hijo de Montero Ríos, como representante de la empresa Iberia Concesionaria se hizo cargo de la concesión de la línea Vigo-Mondariz. En el nuevo proyecto ya vemos directamente vinculada a la burguesía local. Las familias Palacios, Sanjurjo, Tapias, Curbera y Peinador eran los apellidos de los miembros de los comités locales que se constituyeron para fijar libremente el trayecto de la línea y al margen del trazado estipulado por los ingenieros y técnicos. En 1904 el proyecto continuaba a través de la creación de una nueva sociedad en Madrid, la Sociedad Eléctrica del Miño, de la que también forman parte Montero Villegas y el mismo Peinador Vela. El pretexto utilizado en su creación fue la construcción de la línea entre O Porriño y Mondariz aprovechando el

${ }^{50}$ Luis Pericot e Isidro Parga, «Castros de los alrededores de Mondariz-Balneario», La Temporada, 17.6.1928.

${ }^{51}$ En esta sección aparecen semblanzas de Murguía, José López y Riestra (marqués de Riestra), José García Barbón, Antonio Sanjurjo Badía, María Castaña, Juana de Castro, María Pita y otros personajes.

${ }_{52}$ Mondariz. Suplemento a La Temporada, 20.3 y 20.9.1916; 15.2.1917.

53 Ibidem, 40, 20.10.1920, pp. 789-798.

${ }^{54}$ Los datos referidos al proyecto de la línea tranviaria entre Vigo y Mondariz están sacados de Antonio Giráldez, Recordando los tranvías de Vigo..., op. cit., 149-176. 
saldo de agua de Barral, en el ayuntamiento de Castrelo do Miño; también se abrió una suscripción popular a través de la que se obtuvieron 8.000 acciones de 500 pesetas cada una, lo que permitió llegar a un capital inicial de inversión de cuatro millones de pesetas ${ }^{55}$. Pero el hecho de coincidir el recorrido con las obras de la carretera que uniría Ponteareas y Mondariz, entre 1906 y 1908, llevó a que continuasen las demoras. En julio de 1911 se retoma el tema cuando la empresa bilbaína Sociedad Anónima Iberia Concesionaria consigue la titularidad de las obras y dos años después, en 1913, esta traspasa sus derechos a Enrique Peinador Vela, quien en noviembre de ese año acuerda con la Sociedad Hispano-Belga un convenio para la constitución de la sociedad Tranvía de Mondariz a Vigo.

Un nuevo trazado proyectaba comunicar Mondariz con O Porriño a través de Ponteareas. La elección de O Porriño para la ubicación de una subestación está relacionada con el hecho de ser este un pueblo rico en agricultura y ganadería, con una presencia importante de sindicatos agrarios no confesionales y con una situación privilegiada en cuanto a comunicaciones. En la villa del Louro se cruzaban las carreteras más importantes de la provincia de Pontevedra, caso de la carretera de Castilla entre Vigo y Villacastín (1833) y la comunicación ferroviaria de la línea Ourense-Vigo desde el 19 de junio de 1881, lo que facilitaba el envío de remesas de carne al interior del estado. Tales privilegios habían traído un importante desarrollo económico e industrial incluso de la vecina Ponteareas, lo que justificaría el interés de los burgueses implicados en que la línea atravesara dicho ayuntamiento. Pero cuando en 1914 los titulares belgas abandonan la empresa por dificultades mantenidas con los accionistas españoles, la situación derivó en la impopularidad de la figura de Enrique Peinador, el promotor del proyecto.

Tal circunstancia llevó a Peinador Lines a organizar en la ciudad de Pontevedra una reunión con los accionistas en el mes de febrero de 1914 para salvar el proyecto. El encuentro se saldó con el nombramiento de un Consejo de Administración de la sociedad Tranvía de Mondariz a Vigo, con un capital de dos millones de pesetas, de la que él era el secretario. Aunque se retomaron las obras, el comienzo de la Gran Guerra en el verano de 1914 supuso la paralización del mercado internacional y los materiales para la construcción de la línea comenzaron a retrasarse e incluso a no llegar. A la altura del año 1916 las obras no tenían un ritmo continuado

55 Ibidem, p. 154.

Historia Contemporánea 50: 105-132 
y en el mes de octubre de 1917 fallecía el gran impulsor del llamado Tranvía de Mondariz, Enrique Peinador Vela.

En 1918 el proyecto toma un nuevo impulso tras una subvención de la Diputación de Pontevedra y la adquisición de material en EE. UU. y en Suecia. La Sociedad pasa a cotizar en la Bolsa de Madrid en 1919 y entre febrero y marzo de 1920 se puso en funcionamiento el único tramo construido de la línea, el de Vigo a O Porriño, que ocupaba un tiempo aproximado de dos horas. El último tramo de la línea ya solo interesaría directamente a la familia Peinador como propietaria que era del complejo termal, lo que determinaría en buena medida que el resto de los burgueses locales abandonasen el proyecto. Además, a partir de la década de 1920 los baños de mar y sol ofrecían cada vez mejores condiciones en el desarrollo de la idea de ocio y diversión, un entretenimiento que además se completaba con la oferta cultural de teatros, cines y cafés de la ciudad olívica. Esta competencia sería ya insalvable para la ville d'eaux de Mondariz, de condición cada vez más residencial y elitista, frente al ocio de masas de las playas urbanas.

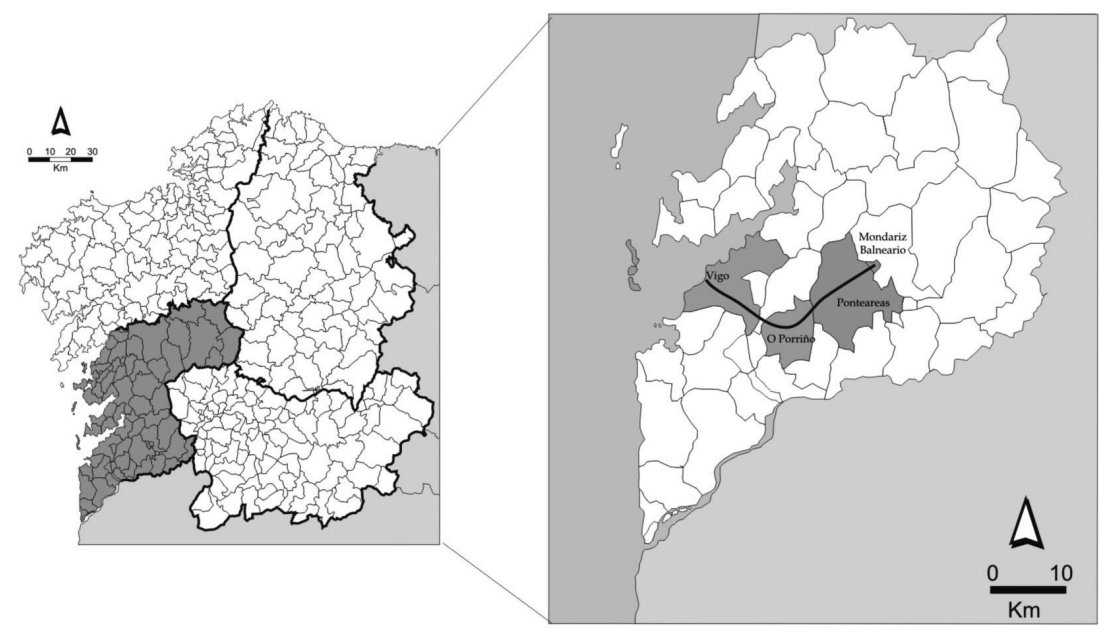

Mapa 2

Delimitación del proyecto de la línea tranviaria Vigo-Mondariz en la Provincia de Pontevedra.

Fuente: elaboración propia. 
De lo que no cabe duda alguna es del hecho de que el tranvía mejoró no solo las comunicaciones y las relaciones entre el puerto de Vigo y el balneario de Mondariz sino también las actividades comerciales entre $\mathrm{O}$ Porriño y alrededores (Ponteareas) al convertirse en el medio de transporte para las empresas familiares y locales (lecheras, panaderos, leñeros, etc.) y los obreros de las conserveras, los astilleros y las empresas auxiliares localizadas en la ría de Vigo. Prueba evidente es la información que ofrecen los datos estadísticos referidos a los movimientos de viajeros del tranvía O Porriño - Vigo entre los años 1930 y 1957, que alcanzaron un máximo de 905.318 pasajeros en $1950^{56}$.

\begin{tabular}{cc}
$\begin{array}{c}\text { Movimiento de viajeros del tranvía Vigo-O Porriño } \\
\text { (denominado Mondariz-Vigo), } 1930-1936\end{array}$ \\
\hline Ejercicio & Viajeros \\
\hline 1930 & 99.378 \\
1934 & 260.856 \\
1938 & 342.306 \\
1942 & 796.531 \\
1946 & 716.147 \\
1950 & 905.318 \\
1954 & 809.519 \\
\hline
\end{tabular}

Fuente: Antonio Giráldez, Recordando los tranvías de Vigo..., op. cit., pp. 169.

\section{Conclusiones}

Los últimos años del siglo XIX y las primeras décadas del XX implicaron un cambio global en la realidad de España. El proceso de modernización generalizado traspasó el terreno económico y llegó a lo social y cultural. Estas transformaciones no solo acontecieron en las grandes urbes y ciudades representativas como lugares de ocio y de disfrute del período estival, caso de San Sebastián y Santander, sino también en otras pobla-

56 En 1960 la sociedad Tranvía de Mondariz a Vigo fue absorbida por Tranvías Eléctricos de Vigo y en febrero de 1967 finaliza definitivamente la actividad de la línea. 
ciones de menor entidad para la época como Vigo, donde la eclosión industrial derivada de los productos del mar y el consecuente desarrollo de una cultura urbana moderna alentó la moderna industrialización de Galicia y dotó a la a ciudad de equipamientos característicos de las ciudades modernas europeas: alameda, avenidas y plazas públicas, estación de ferrocarril y tranvía, una arquitectura de apariencia monumental que constituía los hitos de la ciudad burguesa y el desarrollo del turismo (veraneo) a partir de los baños de mar.

A pocos kilómetros hacia el interior de la provincia, una aldea denominada Troncoso se convertía en centro modélico de salud y ocio, una de las empresas turísticas en la España del momento. En Mondariz, desde finales del siglo XIX la urbanización, el ajardinamiento y los edificios emblemáticos promovidos por la familia Peinador también destacaban por su valor artístico. Un enclave accesible para la economía de burgueses y ociosos portugueses, ingleses y del resto de la geografía española sobre todo y donde la misma población local se puso al servicio de la nueva industria turística que llegaba con ellos. El estilismo y el lujo que se potencia en la Belle Époque también llegaron a Galicia y ello permitió la aparición de un nuevo consistorio independiente, Mondariz-Balneario, desde 1924 y gracias a la importancia que había adquirido como enclave turístico del sector termal. Fue un lugar de encuentro de personalidades españolas y extranjeras, además de foco científico y cultural, algo nuevo para la realidad gallega del momento.

En el tándem Vigo-Mondariz la mezcla de lo rural y lo urbano, lo tradicional y lo moderno, también propició el desarrollo del turismo. La estética del puerto y los barrios de pescadores reforzaron el atractivo de la cultura local para disfrutar de los baños de mar, que junto con el lujo y confort del balneario de Mondariz llevaron a situar dichos enclaves en los mapas de los turistas desde comienzos del siglo XX, factor decisivo en el cambio hacia la nueva estructura socioeconómica y cosmopolita. El importante papel desempeñado por la burguesía local viguesa y la familia Peinador en Mondariz propiciaron el impulso de infraestructuras concretas como la pretendida conexión tranviaria entre ambos puntos. Solo con modernos medios de comunicación se podría atender a la creciente demanda turística, española y extranjera, igual que habían hecho previamente con la ampliación del puerto.

Vigo se configura así como centro urbano moderno y asume la función de cabeza rectora de la aglomeración urbana que se extiende por la ría del mismo nombre y Mondariz pasa a ser un lugar citado en las cró- 
nicas de viajes, lo que colocó el complejo en la lista de las villes d'euax como Panticosa, Vichy o Baden-Baden. Desde comienzos del siglo XX se convirtió en un signo de modernidad gracias al tipo de ocio que propiciaba, un lugar seductor para visitar y disfrutar.

La interacción entre el mundo tradicional de la pesca y las nuevas industria modernas, entre las que se encontraba el sector turístico relacionado tanto con el termalismo como con los baños de mar, queda patente en la ciudad de Vigo y el vecino balneario de Mondariz. Ambos aspecto no se deben entender como categorías mutuamente excluyentes, todo lo contrario. Durante los meses de verano el tándem Vigo-Mondariz traería importantes repercusiones en el desarrollo del turismo en Galicia desde 1885. «Para enfermos y sanos, para turistas y curiosos, Mondariz [y Vigo] constituye[ron] (...) lugar[res] de reposo lleno[s] de gratos refinamientos europeos (...)» [Mondariz-Vigo-Santiago. Guía del Turista, p. 6]. 